\title{
Serum and Urinary Malondialdehyde (MDA), Uric acid, and Protein as markers of perinatal asphyxia
}

\author{
Sawsan Mahmoud El Bana ${ }^{1}$, Sheren Esam Maher ${ }^{2}$, Amani Fawzy Gaber ${ }^{3}$, Sanaa Shaker Aly ${ }^{4}$
}

\author{
${ }^{1}$ Professor, Department of Pediatric, Faculty of Medicine, Minia University, Minia, Egypt \\ ${ }^{2}$ Assistant Professor, Department of Pediatric, Faculty of Medicine, Minia University, Minia, Egypt \\ ${ }^{3}$ Ph.D., Department of Pediatric, Qena Faculty of Medicine, South Valley University, Qena, Egypt \\ ${ }^{4}$ Lecturer, Department of Clinical and Chemical Pathology, Qena Faculty of Medicine, South Valley University, \\ Qena, Egypt
}

\section{Type of article: Original}

\begin{abstract}
Introduction: Perinatal asphyxia (PA) is among the leading causes of neonatal morbidity and death in neonatal intensive care units (NICUs). The aims of this research were to determine the concentrations of malondialdehyde (MDA), urine MDA, uric acid, and protein in the cord blood of neonates with perinatal asphyxia and to determine their relationship with the severity of perinatal asphyxia.

Methods: This matched case-control study was conducted from October 2012 to March 2013. All of the cases and controls were selected from the Gynecology \& Obstetrics Department and the NICUs, at Qous Central Hospital in Qena, Egypt. We allocated 20 full-term neonates who had perinatal asphyxia to the case group. Also, we selected 20 healthy neonates for the control group. The subjects were matched with respect to age and gender. At birth and 48 hours later, measurements were made of MDA in cord blood and urine, and uric acid, protein, and creatinine also were measured in both groups. The data were analyzed by SPSS, version 17, using the independent-samples t-test, ANOVA, Tukey's test, and Spearman's correlation coefficient.

Results: At birth and $48 \mathrm{hr}$ later, the newborns' with PA had significantly higher levels of MDA in the cord blood, mean urinary uric acid/creatinine (UUA:Cr), protein/creatinine (UP:Cr), and MDA/creatinine ratio (UMDA:Cr) than the controls; their PA levels were correlated with the degree of hypoxic-ischemic encephalopathy (HIE). The babies who died due to PA had significantly higher levels of cord blood MDA, and they also had higher UUA:Cr, UP:Cr, and UMDA:Cr ratios than the babies who survived.

Conclusion: The concentration of MDA in cord blood can be used as a diagnostic marker of oxidative stress in asphyxiated neonates. The ratios of the urinary excretion rates of uric acid, protein, and MDA to creatinine increased as the severity of perinatal asphyxia and associated brain damage increased.

Keywords: Oxidative Stress, perinatal Asphyxia, Malondialdehyde, MDA
\end{abstract}

\section{Introduction}

Perinatal asphyxia (PA) is an important cause of perinatal mortality and lifelong neurodevelopmental morbidity (1, 2). There is increasing evidence that a substantial amount of damage occurs upon delivery and up to a few days after reperfusion and reoxygenation $(3,4)$. Adenosine diphosphate (ADP) and adenosine monophosphate (AMP) are reported to accumulate in asphaxia, which causes accumulation of adenosine, inosine, and hypoxanthine (5). These substances are channelized to purine catabolism, which leads to the generation of uric acid, resulting in increased urinary excretions of uric acid (3). Reperfusion in PA is known to be a contributing factor in oxidative stress $(6,7)$. Numerous studies have suggested that free radicals may cause hypoxic ischem $\neg$ ic damage to the brain (4). Since free radicals have a relatively short half-life and are highly reactive, it is difficult to determine their levels accurately. Thus, they are must be determined indirectly in the human body by measuring some antioxidant enzymes, i.e., catalase and glutathione peroxidase, antioxidant vitamins (vitamins E, C, and A), transition metals,

\section{Corresponding author:}

Assistant Professor Dr. Sheren Esam Maher, Department of Pediatric, Faculty of Medicine, Minia University, Minia, Egypt. Tel: +20862334376, Email: Sherenesammaher@yahoo.com

Received: March 03, 2016, Accepted: May 04, 2016, Published: July 2016

iThenticate screening: May 03, 2016, English editing: June 02, 2016, Quality control: July 04, 2016

(C) 2016 The Authors. This is an open access article under the terms of the Creative Commons Attribution-NonCommercialNoDerivs License, which permits use and distribution in any medium, provided the original work is properly cited, the use is non-commercial and no modifications or adaptations are made. 
i.e., copper, iron, and zinc, and by-products of lipid peroxidation, such as malondialdehyde (MDA) (8). MDA is a well-known secondary product of lipid peroxidation (9) and it commonly is used as an indicator of lipid peroxidation (10). MDA can be measured easily by the thiobar $\neg$ bituric acid reaction (11), and it can be used as an indicator of injuries to cell membranes (12).

\section{Material and Methods}

\subsection{Research design and ethics}

The matched case-control study was conducted in the Gynecology \& Obstetrics Department and the Neonatal Intensive Care Units (NICUs) in Qous Central Hospital in Qena, Egypt, from October 2012 to March 2013. The research ethics was approved by the Human Research Ethics Committee at Qous Central Hospital. The study was designed to compare two groups that consisted of babies that were matched with respect to age and gender. Thus, there was a group of 20 term AGA (appropriate for gestational age) neonates with PA, and there was a group of 20 healthy neonates as the control group.

\subsection{Selection criteria}

The inclusion criteria in the study were the presence of two or more of the following: Cord blood $\mathrm{pH}<7.1$, Apgar score of $\leq 7$ at five minutes after birth, Meconium stained liquor, Abnormalities of fetal heart rate, and clinical evidence of HIE. The exclusion criteria consisted of the following: neonates with congenital anomalies, congenital infection, hemolytic disease, pre-term infants $<37$ weeks, post-term and umbilical cord anomalies. We also excluded the neonates of mothers who had any chronic illness or any other major complications, such as hypertension and gestational diabetes.

\subsection{Measurements}

All of the subjects were under the following examinations and laboratory measurements: 1) Full Antenatal, Natal, Postnatal and family history; 2) Clinical assessment included gestational age and Apgar score estimation at one and five minutes; 3) General and systemic examinations, especially neurological examinations; 4) Sarnat staging: staging of hypoxic ischemic encephalopathy in the babies who developed neurological manifestations; 5) Measurement of MDA in the cord blood and urine, and uric acid and proteins were determined in both groups at birth and after $48 \mathrm{~h}$.

\subsection{Sample collections}

Urine samples were collected by using a urine collection bag on the first day after birth and after $48 \mathrm{~h}$ after birth. It was the first and/or the second voiding of urine. Samples of approximately 10-15 ml of urine were collected and mixed with $1 \%$ sodium azide and centrifuged at 2500 revolutions per minute (rpm) for 5 min. The supernatant was collected and stored at $-50{ }^{\circ} \mathrm{C}$ until analysis. Cord blood samples were taken from the placental part of the umbilical cord. Free-flowing cord blood was collected in sterile, heparinized, deionized polyethylene. Plasma was separated from blood samples immediately by centrifugation at 2000 revolutions per minute (rpm) for 5 minutes, and it was stored in separate deionized vials at $-20{ }^{\circ} \mathrm{C}$ until it was analyzed. Determination of serum and urinary MDA by using commercial kit from the Biodiagnostic Company, catalog No. 001-0020, urinary uric acid and creatinine by using a commercial kit from Spectrum Company with catalog numbers 325-001 and 234-001, respectively, and urinary protein by using a commercial kit from Stanbiolaboratory (Texas, USA, catalog No. 0345).

\subsection{Statistical analysis}

The data were analyzed by SPSS, version 17, using the independent-samples t-test, ANOVA, Tukey's test, and Spearman's correlation coefficient.

\section{Results}

A group of 20 term AGA (appropriate for gestational age) neonates with perinatal asphyxia were selected as cas es. The cases consisted of four females $(20 \%)$ and 16 males $(80 \%)$ with the mean gestational age of $38.95 \pm 0.88$ weeks. Among the 20 asphyxiated infants, seven (35\%), 10 (50\%), and three (15\%) had stages-1, -2, and -3 hypoxic ischemic encephalopathy, respectively. Ten neonates developed seizures, and seven were irritable. Seventeen neonates $(85 \%)$ survived and were discharged from the hospital, and three $(15 \%)$ died. We found a significant decrease in the mean value of Apgar score at one and five minutes between patients and controls (Table 1). We found that the mean MDA values in the cord blood of newborns with perinatal asphyxia $(6.24 \pm 1.20 \mu \mathrm{M} / \mathrm{L}) \mathrm{were}$ significantly higher than those of the control group $(2.38 \pm 0.30 \mu \mathrm{M} / \mathrm{L})(\mathrm{p}<0.001)$. The mean urinary $\mathrm{MDA}$ :Cr ratios at birth $(2.62 \pm 0.29 \mu \mathrm{g} / \mathrm{mg})$ and after $48 \mathrm{hr}(3.70 \pm 52 \mu \mathrm{g} / \mathrm{mg})$ were elevated significantly in newborns with 
perinatal asphyxia compared to the controls $(1.63 \pm 0.19 \mu \mathrm{g} / \mathrm{mg}$ vs. $1.96 \pm 0.15 ; \mathrm{P}<0.001)$. Also, the mean values of the UUA:Cr ratio at birth $(1.79 \pm 0.46 \mathrm{mg} / \mathrm{mg})$ and after $48 \mathrm{hr}(3.89 \pm 1.14 \mathrm{mg} / \mathrm{mg})$ were elevated significantly in newborns with perinatal asphyxia compared to those in the control group $(1.12 \pm 0.06$ vs. $1.69 \pm 0.24 \mathrm{mg} / \mathrm{mg})(\mathrm{p}<$ 0.001 ). In addition, the mean values of the UP:Cr ratio at birth and after $48 \mathrm{hr}$, i.e., $3.57 \pm 0.00$ and $6.28 \pm 0.67$ $\mathrm{mg} / \mathrm{mg}$, respectively, were elevated significantly in newborns with perinatal asphyxia compared to the controls (1.69 \pm 0.23 vs. $2.32 \pm 0.21 \mathrm{mg} / \mathrm{mg}$, respectively; $\mathrm{p}<0.001$ ) (Table 2). In the current study, there was a significant negative correlation between the level of MDA in the cord blood and the UUA:Cr, UP:Cr, and UMDA:Cr ratios at birth and after $48 \mathrm{hr}$ and the Apgar scores at one and five minutes, respectively (Table 3).

Table 1. Comparison between patients and controls as regards gestational age, birth weight, and Apgar score at one and five minutes

\begin{tabular}{|l|l|l|l|l|}
\hline Variables & Patients; Mean \pm SD (range) & Controls; Mean \pm SD (range) & t & p-value \\
\hline GA & $38.950 \pm 0.887(37.00-40.00)$ & $38.650 \pm 0.933(37.00-40.00)$ & -1.042 & 0.304 \\
\hline B.W. & $3.310 \pm 0.390(2.70-4.40)$ & $3.113 \pm 0.264(2.50-3.60)$ & -1.873 & 0.069 \\
\hline APG1 & $2.200 \pm 1.005(1.00-4.00)$ & $7.150 \pm 0.875(6.00-8.00)$ & 16.610 & $<0.001$ \\
\hline APG5 & $4.800 \pm 0.894(3.00-6.00)$ & $9.250 \pm 0.786(8.00-10.00)$ & 16.710 & $<0.001$ \\
\hline
\end{tabular}

GA: gestational age, B.W.: birth weight, APG1: Apgar at one minute, APG5: Apgar at five minutes

Table 2. Comparison between patients and controls as regards cord blood MDA UP:Cr, UUA:Cr, and UMDA:Cr ratios at birth and after $48 \mathrm{hr}$

\begin{tabular}{|l|l|l|l|}
\hline Variables & Patients $($ Mean $\pm \mathrm{SD})$ & Controls $($ Mean $\pm \mathrm{SD})$ & $\mathrm{p}$-value \\
\hline Cord blood MDA $(\mu \mathrm{M} / \mathrm{L})$ & $6.248 \pm 1.201(5.30-9.50)$ & $2.382 \pm 0.304(1.85-3.10)$ & $<0.001$ \\
\hline $\begin{array}{l}\text { UUA:Cr at birth }(\mathrm{mg} \text { uric acid/mg of } \\
\text { creatinine) }\end{array}$ & $1.793 \pm 0.469(1.27-2.86)$ & $1.129 \pm 0.063(1.00-1.22)$ & $<0.001$ \\
\hline $\begin{array}{l}\text { UUA:Cr after } 48 \mathrm{hr} \text {. (mg uric acid/mg of } \\
\text { creatinine) }\end{array}$ & $3.895 \pm 1.147(2.18-5.86)$ & $1.692 \pm 0.247(1.14-2.10)$ & $<0.001$ \\
\hline UP:Cr at birth $(\mathrm{mg}$ protein/mg of creatinine) & $3.577 \pm 0.560(2.72-4.93)$ & $1.695 \pm 0.231(1.17-1.94)$ & $<0.001$ \\
\hline $\begin{array}{l}\text { UP:Cr after } 48 \mathrm{hr}(\mathrm{mg} \text { protein/mg of } \\
\text { creatinine) }\end{array}$ & $6.285 \pm 0.672(5.20-7.90)$ & $2.321 \pm 0.214(1.73-2.58)$ & $<0.001$ \\
\hline $\begin{array}{l}\text { UMDA:Cr at birth }(\mu \mathrm{g} \text { of MDA/mg of } \\
\text { creatinine) }\end{array}$ & $2.622 \pm 0.292(2.19-3.59)$ & $1.639 \pm 0.199(1.26-1.95)$ & $<0.001$ \\
\hline $\begin{array}{l}\text { UMDA:Cr after } 48 \mathrm{hr}(\mu \mathrm{g} \text { of MDA/mg of } \\
\text { creatinine) }\end{array}$ & $3.709 \pm 0.529(3.10-5.07)$ & $1.965 \pm 0.155(1.55-2.20)$ & $<0.001$ \\
\hline
\end{tabular}

UUA: urinary uric acid, Cr.: creatinine, UP: urinary protein, UMDA: urinary malondialdehyde.

Table 3. Correlation between cord blood MDA, UP:Cr, UUA:Cr and UMDA:Cr ratios at birth and after $48 \mathrm{hr}$ and clinical data of all the patients

\begin{tabular}{|l|l|l|l|l|l|l|l|l|}
\hline \multirow{2}{*}{ Variables } & GA & \multicolumn{2}{l|}{ B.W } & \multicolumn{2}{l|}{ APG1 } & \multicolumn{2}{l|}{ APG5 } & \\
\cline { 2 - 11 } & $\mathrm{R}$ & $\mathrm{p}$-value & $\mathrm{r}$ & $\mathrm{p}$-value & $\mathrm{r}$ & $\mathrm{p}$-value & $\mathrm{r}$ & $\mathrm{p}$-value \\
\hline Cord blood MDA & -0.017 & 0.942 & 0.046 & 0.848 & -0.623 & $0.003^{*}$ & -0.774 & $<0.001$ \\
\hline UUA:Cr at birth & -0.037 & 0.878 & 0.062 & 0.795 & -0.666 & $<0.001^{*}$ & -0.784 & $<0.001$ \\
\hline UUA:Cr after 48hr. & -0.106 & 0.657 & 0.113 & 0.635 & -0.698 & $<0.001^{*}$ & -0.810 & $<0.001$ \\
\hline UP:Cr at birth & 0.014 & 0.953 & 0.071 & 0.766 & -0.605 & $0.005^{*}$ & -0.793 & $<0.001$ \\
\hline UP:Cr after 48hr. & -0.085 & 0.721 & 0.046 & 0.848 & -0.683 & $<0.001^{*}$ & -0.823 & $<0.001$ \\
\hline UMDA:Cr at birth & 0.043 & 0.856 & 0.225 & 0.340 & -0.508 & $0.022^{*}$ & -0.700 & $<0.001$ \\
\hline UMDA:Cr after 48hr. & 0.057 & 0.810 & 0.166 & 0.485 & -0.588 & $0.006^{*}$ & -0.817 & $<0.001$ \\
\hline
\end{tabular}

GA: gestational age, B.W.: birth weight, APG1: Apgar at one minute, APG5: Apgar at five minutes, UUA: urinary uric acid, Cr.: creatinine, UP: urinary protein, UMDA: urinary malondialdehyde

In the current study, cases with HIE were split into three categories according to Sarnat's grading, i.e., grades I, II, and III. There were highly significant differences between the MDA in cord blood and the UUA:Cr, UP:Cr, and UMDA:Cr ratios at birth and after $48 \mathrm{hr}$ and grading of encephalopathy $(\mathrm{p}<0.001)$. There was a highly significant difference between stages I and II, between stages I and III, and also between stages II and III regarding the MDA in the cord blood and the UUA:Cr ratios at birth and after $48 \mathrm{hr}$ and UP:Cr after $48 \mathrm{hr}(\mathrm{p}<0.001)$ (Table 4). In the present study, the HIE cases also were divided into those who survived and were discharged from hospital $(\mathrm{n}=17)$ and those who died $(\mathrm{n}=3)$. No significant difference was found in birth weight or Apgar score at one minute 
between those who survived and those who died of perinatal asphyxia, but there was a significant difference between them regarding their Apgar scores at five minutes $(p<0.001)$. Also, the cases who died of perinatal asphyxia had significantly higher MDA levels in their cord blood and their UUA:Cr, UP:Cr, and UMDA:Cr ratios also were higher at birth and after $48 \mathrm{hr}$ than the babies who survived (Table 5).

Table 4. Cord blood MDA, UP:Cr, UUA:Cr and UMDA:Cr ratios at birth and after $48 \mathrm{hr}$. in various subgroups of HIE among all the patients.

\begin{tabular}{|c|c|c|c|c|c|c|c|c|c|}
\hline \multirow[t]{3}{*}{ Variables } & \multicolumn{9}{|l|}{ Grading } \\
\hline & \multirow{2}{*}{$\begin{array}{l}\text { I (Mean } \pm \\
\text { SD) }\end{array}$} & \multirow{2}{*}{$\begin{array}{l}\text { II (Mean } \pm \\
\text { SD) }\end{array}$} & \multirow{2}{*}{$\begin{array}{l}\text { III (Mean } \pm \\
\text { SD) }\end{array}$} & \multirow{2}{*}{$\begin{array}{l}\text { ANOVA } \\
\mathrm{p}\end{array}$} & \multicolumn{2}{|c|}{ Spearman test } & \multicolumn{3}{|c|}{ Tukey's test } \\
\hline & & & & & $\mathrm{r}$ & $\mathrm{p}$ & I \& II & I \& III & $\begin{array}{l}\text { II \& } \\
\text { III }\end{array}$ \\
\hline $\begin{array}{l}\text { Cord blood } \\
\text { MDA }\end{array}$ & $5.407 \pm 0.084$ & $6.050 \pm 0.310$ & $8.867 \pm 0.551$ & $<0.001$ & 0.865 & $<0.001$ & $<0.001$ & $<0.001$ & $<0.001$ \\
\hline $\begin{array}{l}\text { UUA:Cr at } \\
\text { birth }\end{array}$ & $1.338 \pm 0.096$ & $1.867 \pm 0.246$ & $2.606 \pm 0.226$ & $<0.001$ & 0.905 & $<0.001$ & $<0.001$ & $<0.001$ & $<0.001$ \\
\hline $\begin{array}{l}\text { UUA:Cr after } \\
48 \mathrm{hr} \text {. }\end{array}$ & $2.656 \pm 0.325$ & $4.234 \pm 0.578$ & $5.657 \pm 0.275$ & $<0.001$ & 0.921 & $<0.001$ & $<0.001$ & $<0.001$ & $<0.001$ \\
\hline UP:Cr at birth & $170 \pm 0.262$ & 3.531 & $4.680 \pm 0.265$ & $<0.001$ & 0.777 & $<0.001$ & 0.028 & $<0.001$ & $<0.001$ \\
\hline $\begin{array}{l}\text { UP:Cr after } \\
48 \mathrm{hr} \text {. }\end{array}$ & $5.640 \pm 0.314$ & $6.398 \pm 0.291$ & $7.416 \pm 0.421$ & $<0.001$ & 0.778 & $<0.001$ & $<0.001$ & $<0.001$ & $<0.001$ \\
\hline $\begin{array}{l}\text { UMDA:Cr at } \\
\text { birth }\end{array}$ & $2.388 \pm 0.124$ & $2.635 \pm 0.060$ & $3.124 \pm 0.421$ & $<0.001$ & 0.815 & $<0.001$ & 0.021 & $<0.001$ & $<0.001$ \\
\hline $\begin{array}{l}\text { UMDA:Cr } \\
\text { after 48hr. }\end{array}$ & $3.311 \pm 0.138$ & $3.678 \pm 0.281$ & $4.744 \pm 0.284$ & $<0.001$ & 0.842 & $<0.001$ & 0.017 & $<0.001$ & $<0.001$ \\
\hline
\end{tabular}

UUA: urinary uric acid, Cr.: creatinine, UP: urinary protein, UMDA: urinary malondialdehyde

Table 5. Mean and SD (range) of birth weight, Apgar score, urinary uric acid, protein and MDA to creatinine ratios in cases of perinatal asphyxia

\begin{tabular}{|l|l|l|l|l|l|l|}
\hline \multirow{2}{*}{ Variables } & \multicolumn{3}{|l|}{ Perinatal asphyxia cases } & \multicolumn{2}{l|}{ t-test } \\
\cline { 2 - 8 } & Survived & \multicolumn{2}{l|}{ Dead } & \multicolumn{2}{l|}{} \\
\cline { 2 - 8 } & Range & Mean \pm SD & Range & Mean \pm SD & t & p-value \\
\hline B.W. & $2.7-4.4$ & $3.30 \pm 0.42$ & $3.2-3.6$ & $3.37 \pm 0.21$ & -0.269 & 0.791 \\
\hline APG1min & $1.0-4.0$ & $2.35 \pm 1.00$ & $1.0-2.0$ & $1.33 \pm 0.58$ & 1.698 & 0.107 \\
\hline APG5min & $3.0-6.0$ & $5.00 \pm 0.79$ & $3.0-4.0$ & $3.33 \pm 0.58$ & 4.238 & $<0.001$ \\
\hline Cord blood MDA & $5.3-8.5$ & $5.90 \pm 0.75$ & $6.6-9.5$ & $8.23 \pm 1.48$ & -4.306 & $<0.001$ \\
\hline UUA:Cr at birth & $1.3-2.4$ & $1.65 \pm 0.33$ & $2.4-2.9$ & $2.60 \pm 0.23$ & -4.710 & $<0.001$ \\
\hline UUA:Cr after 48hr. & $2.2-5.3$ & $3.61 \pm 0.97$ & $4.9-5.9$ & $5.52 \pm 0.52$ & -3.257 & $<0.004$ \\
\hline UP:Cr at birth & $2.7-4.0$ & $3.38 \pm 0.31$ & $4.4-4.9$ & $4.68 \pm 0.26$ & -6.845 & $<0.001$ \\
\hline UP:Cr after 48hr. & $5.2-6.9$ & $6.09 \pm 0.48$ & $7.1-7.9$ & $7.42 \pm 0.42$ & -4.465 & $<0.001$ \\
\hline UMDA:Cr at birth & $2.2-2.8$ & $2.55 \pm 0.16$ & $2.6-3.6$ & $3.05 \pm 0.52$ & -3.446 & $<0.003$ \\
\hline UMDA:Cr after 48hr. & $3.1-4.5$ & $3.55 \pm 0.35$ & $4.2-5.1$ & $4.63 \pm 0.43$ & -4.803 & $<0.001$ \\
\hline
\end{tabular}

B.W.: birth weight, APG1: Apgar at one minute, APG5: Apgar at five minutes, UUA: urinary uric acid, Cr.: creatinine, UP: urinary protein, UMDA: urinary malondialdehyde

\section{Discussion}

In developing countries, PA is the most significant cause of hypoxic ischemic brain damage in full-term newborns (13). Therefore, defining the severity of encephalopathy is particularly useful for adjusting the medical treatments and estimating the long-term outcomes of asphyxiated infants in clinical practice. MDA is one of the well-known secondary products of lipid peroxidation (10). MDA as measured by thiobarabituric acid reactivity is a sensitive index of oxidative stress that is well known and clinically used. In the present study, there was a significant decrease in Apgar score at one and five minutes in patients compared to the controls. These findings are in accordance with those of Florio et al. (14), who reported that Apgar scores at the one and five minutes were significantly lower in the patients' group than in the controls. In contrast, Dede et al. reported that there was highly statistically significant difference between the study group and control group regarding the Apgar score at one minute only (15). In the current study, the mean MDA level in the cord blood was significantly higher in newborns with perinatal asphyxia 
than in the control group. These findings were in agreement with those of Kumar et al. (12), who reported that the MDA concentration in the umbilical cord blood of the study group was significantly higher than that of the control group, which indicated the association between perinatal asphyxia and oxidative stress. Since MDA is soluble in water, it appears in urine. The level of MDA in the urine has been claimed to reflect the level of lipid peroxidation in vivo (16). The results of the present study indicated that the mean UMDA:Cr ratio at birth, i.e., $2.62 \pm 0.29 \mu \mathrm{g} / \mathrm{mg}$, was elevated significantly in newborns with perinatal asphyxia compared to that of the controls $[1.63 \pm 0.19 \mu \mathrm{g} / \mathrm{mg}]$. These findings were in accordance with those of Banupriya et al. (17), who found that the UMDA:Cr ratio in the study group was significantly higher than the UMDA:Cr ratio in the control group. Furthermore, the present study indicated that the mean UMDA:Cr ratio after $48 \mathrm{hr}(3.70 \pm 0.52 \mu \mathrm{g} / \mathrm{mg})$ was elevated significantly in newborns with perinatal asphyxia compared to that of the controls $(1.96 \pm 0.15 \mu \mathrm{g} / \mathrm{mg})$. This was in accordance with a study conducted by Pimentel et al. (18). They reported that UMDA levels were significantly higher in eight days in hypoxic-ischemic (HI) group when compared with the control, returning to baseline levels 60 days after HI. They also reported that the increase of lipid peroxidation in the urine within this period may be related due to the inadequate scavenging ability of the immature nervous system. The results of the present study indicated that the mean UA:Cr ratio at birth was significantly elevated in newborns with perinatal asphyxia compared to the controls, and these findings were in agreement with those of Chen et al. (18), who found that urinary ratio of UA to Cr was significantly higher in both full-term and pre-term infants with PA than in those without PA. The increase can be explained by the fact that uric acid is a product of ATP catabolism, which is known to be enhanced in PA due to enhanced xanthineoxdiase activity on reperfusion, and this might contribute to oxidative stress in PA (3). Furthermore, the mean UUA:Cr ratio after $48 \mathrm{hr}$ was significantly elevated in newborns with perinatal asphyxia compared to the controls. In a study conducted by Pimentel et al. (19), they reported that urinary UA levels were significantly higher after eight days in the HIE group than in the control group. They also reported that the increase in UA levels indicated a purinic degradation during these first days of HIE. The results of the present study indicated that the mean UP:Cr ratio at birth was significantly elevated in newborns with perinatal asphyxia compared to the controls, and these findings were in accordance with those of Banupriya et al. (17), who found that the UP:Cr ratio in the study group was significantly higher than it was in the control group. Also, the mean UP:Cr ratio after $48 \mathrm{hr}$ was significantly elevated in newborns with perinatal asphyxia compared to the controls. In the present study, there was a highly-significant positive correlation between cord blood MDA, UP:Cr, UUA:Cr and UMDA:Cr ratios at birth and after $48 \mathrm{hr}$ and grading of encephalopathy, indicating that the urinary excretion rate depended on the degree of renal impairment that was associated with the severity of asphyxia (20). These findings are supported by Banupriya et al. (17), who reported that there was a significant positive correlation between values of UP:Cr, UUA:Cr, and UMDA:Cr and HIE staging. This study indicated that there was a significant correlation between the severity of cerebral damage (as measured by Sarnat's grading) and cord blood MDA, UP:Cr, UUA:Cr and UMDA:Cr ratios. Therefore, this approach could be used to evaluate the prognosis of neonates with HIE. In addition to clinical grading, the neonates with HIE also were divided into two groups, i.e., those who died and those who survived and were discharged from the Hospital. The babies who died of perinatal asphyxia had significantly higher cord blood MDA, UP:Cr, UUA:Cr, and UMDA:Cr ratios at birth and after $48 \mathrm{hr}$ than the babies who survived. This can be explained by the severe renal damage that occurred in the babies who died. These findings are in accordance with those of Mondal et al. (20), who reported that blood MDA values at birth and after 48 hours were significantly higher among the cases that died than in those who survived $(\mathrm{p}<0.05)$. Thus, cord blood MDA, UP:Cr, UUA:Cr, and UMDA:Cr ratios could potentially be used as criteria for evaluating the prognosis and mortality of neonates with HIE.

\section{Conclusions}

The cord blood MDA concentration in asphyxiated neonates represents a diagnostic marker of oxidative stress. The excretion rates of UP:Cr, UUA:Cr, UMDA:Cr, and MDA:Cr were increased with the severity of perinatal asphyxia and associated brain damage, and they represent prognostic markers for neurological outcome. Early assessment of the severity of an acute cerebral lesion may provide a very useful basis for preventive or therapeutic decisions in HIE patients.

\section{Acknowledgments:}

The authors are thankful to the staff members of the Gynecology \& Obstetrics Department and the Neonatal Intensive Care Units (NICUs) at Qous Central Hospital in Qena, Egypt, for supporting this study.

\section{Conflict of Interest:}

There is no conflict of interest to be declared. 


\section{Authors' contributions:}

All authors contributed to this project and article equally. All authors read and approved the final manuscript.

\section{References:}

1) Dilenge ME, Majnemer A, Shevell MI. Long-term developmental outcome of asphyxiated term neonates. J Child Neurol. 2001; 16(11): 781-92. doi: 10.1177/08830738010160110201. PMID: 11732762.

2) Simon NP. Long-term neurodevelopmental outcome of asphyxiated newborns. Clin Perinatol. 1999; 26(3): 767-78. PMID: 10494478 .

3) Fellman V, Raivio KO. Reperfusion injury as the mechanism of brain damage after perinatal asphyxia. Pediatr Res. 1997; 41(5): 599-606. doi: 10.1203/00006450-199705000-00001. PMID: 9128279.

4) Ogihara T, Hirano K, Ogihara H, Misaki K, Hiroi M, Morinobu T, et al. Non protein bound transition metal and hydroxyl radical generation in CSF fluid of newborn infants with hypoxic ischemic encephalopathy. Pediatric research. 2003; 53(4): 594-9. doi: 10.1203/01.PDR.0000054685.87405.59. PMID: 12612209.

5) Poulsen JP, Oyasaeter S, Sanderud J, Rognum TO, Saugstod OD. Hypoxanthine, xanthine, and uric acid concentration in the cerebrospinal fluid, plasma and urine of hypoxemic pigs. Pediatr Res. 1990; 28(5): 477-81. doi: 10.1203/00006450-199011000-00012. PMID: 2255571.

6) Katz LM, Young AS, Frank JE, Wang Y, Park K. Regulated hypothermia reduces brain oxidative stress after hypoxic-ischemia. Brain Res. 2004; 1017(1-2): 85-91. doi: 10.1016/j.brainres.2004.05.020. PMID: 15261103.

7) Shoji H, Koletzko B. Oxidative stress and antioxidant protection in the perinatal period. Curr Opin Clin Nutr Metab Care. 2007; 10(3): 324-8. doi: 10.1097/MCO.0b013e3280a94f6d. PMID: 17414502.

8) Butterfield DA, Castegna A, Drake J, Scapagnini G, Calabrese V. Vitamin E and neurodegenerative disorders associated with oxidative stress. Nutr neurosci. 2002; 5(4): 229-39. doi: 10.1080/10284150290028954. PMID: 12168685.

9) Tezcan E, Atmaca M, Kuloglu M, Ustundag B. Free radicals in patients with post-traumatic stress disorder. Eur Arch Psychiatry Clin Neurosci. 2003; 253(2): 89-91. PMID: 12799747.

10) Karatas F, Karatepe M, Baysar A. Determination of free malondialdehyde in human serum by highperformance liquid chromatography. Anal biochem. 2002; 311(1): 76-9. doi: 10.1016/S00032697(02)00387-1. PMID: 12441155.

11) Karatas F, Halifeoglu I, Karatepe M, Konar V, Canatan H, Colak R. Evaluation of changes in levels of serum selenium, MDA and antioxidant vitamins (A, E, C) in diabetic patients. Arastirma. 2006; 20(6): 391 5.

12) Kumar A, Panigrahi I, Basu S, Dash D. Urinary malondialdehyde levels in newborns following delivery room resuscitation. Neonatology. 2008; 94(2): 96-9. doi: 10.1159/000116633. PMID: 18277056.

13) Trollman R, Schoof E, Beinder E, Wenzel D, Rascher W, Dotsch J. Adrenomedullin gene expression in human placental tissue and leukocytes: a potential marker of severe tissue hypoxia in neonates with birth asphyxia. Eur j Endocrinol. 2002; 147(5): 711-16. PMID: 12444904.

14) Florio P, Luisi S, Moataza B, Torricelli M, Iman I, Hala M, et al. High urinary concentrations of activin A in asphyxiated full-term newborns with moderate or severe hypoxic ischemic encephalopathy. Clin Chem. 2007; 53(3): 520-2. PMID: 17259240.

15) Dede FS, Guney Y, Dede H, Koca C, Dilbaz B, Bilgihan A. Lipid peroxidation and antioxidant activity in patients in labor with non reassuring fetal status. Eur j obstet Gynecolo Reprod Biol. 2006; 124(1): 27-31. PMID: 15950366.

16) Drury JA, Nycyk JA, Cooke RW. Comparison of urinary and plasma malondialdehyde in preterm infants. Clin Chim Acta. 1997; 263(2): 177-85. PMID: 9246422.

17) Banupriya C, Ratnakar, Doureradjou P, Mondal N, Vishnu B, Koner BC. Can urinary excretion rate of malondialdehyde, uric acid and protein predict the severity and impending death in perinatal asphyxia? Clin Biochem. 2008; 41(12): 968-73. doi: 10.1016/j.clinbiochem.2008.04.011. PMID: 18471999.

18) Chen HJ, Yau KI, Tsai KS. Urinary uric acid/creatinine ratio as an additional marker of perinatal asphyxia. J Formos Med Assoc. 2000; 99(10): 771-4. PMID: 11061072.

19) Pimentel VC, Pinheiro FV, Kaefer M, Moresco RN, Moretto MB. Assessment of uric acid and lipid peroxidation in serum and urine after hypoxia-ischemia neonatal in rats. Neuro Sci. 2011; 32(1): 59-65. doi: 10.1007/s10072-010-0393-3. PMID: 20730463.

20) Mondal N, Bhat BV, Banupriya C, Koner BC. Oxidative stress in perinatal asphyxia in relation to outcome. Indian j pediatr. 2010; 77(5): 515-7. doi: 10.1007/s12098-010-0059-4. PMID: 20401708. 